Send your letters to the Editor,

British Dental Journal,

64 Wimpole Street

London

W1G 8YS

Email bdj@bda.org

Priority will be given to letters less than 500 words long.

Authors must sign the letter, which

may be edited for reasons of space.

\section{SURPRISING FERVOUR}

Sir, the letter No to BDA (BDJ 2010; 208: 379) raises some very important points and I am grateful to the authors for so candidly expressing the views of their collective memberships.

I have listened to much debate in the BDA's Executive Board and Representative Body on the subject of broadening the membership of the Association. These discussions generate strong feelings on both sides, but the one feature that is common is the total respect and recognition of all the members of the dental team. The BDA is very supportive of the DCP organisations and is on record as encouraging all professionals to join their own professional body. Whether or not the BDA opened its doors to other groups, I think this would remain our position as we recognise the important individual needs of particular groups. So, given that broader membership would merely give DCPs the freedom of choice to join, in addition to their own body, I am rather surprised by the fervour of this broad rejection of such a move even before it has been offered.

Still it is very helpful to have this information. From the mandated leaders and spokespeople of 50,000 dental care professionals, the message to the $\mathrm{BDA}$ is received and understood. I hope the individual dental care professionals who have expressed slightly different views will understand why this issue has been so complex.

On a point of clarification, the BDA does not offer professional indemnity cover and has no intention to do so. We believe that it is an important and complex field of activity that is better delivered by specialists in that area with a proven track record.

P. Ward, BDA Chief Executive DOI: 10.1038/sj.bdj.2010.452

\section{NOT THE ARGUMENT}

Sir, Professor Paul Wright (Long term short cuts; BDJ 2010; 208: 241) sets out very clearly the difficulties facing academic dentistry which are easy to understand and which present a real danger to the standards of education of dental students.

It is clear that in many respects the position of dental academe is unique. However, Professor Wright's claim that 'Higher Education in dentistry is one of the few university disciplines that can truly be said to provide public and economic benefits to the nation' is decidedly not the argument to use in order to convey these difficulties to those who might help to address them. Indeed, I imagine such a statement will hardly commend itself to Professor Wright's Vice-Chancellor; it doesn't to me even as a sympathiser!

R. Bettles

By email

DOI: 10.1038/sj.bdj.2010.453

\section{ORTHODONTIC STIMULUS}

Sir, the aetiology of malocclusion in modern human populations remains an intriguing, complex and important facet of both academic and clinical areas of interest. It is not the only subject in orthodontics that presents conflicting data, conclusions, and the need for continual updating in response to new knowledge in the applied and basic scientific community within and beyond the dental profession. And certainly not the only compelling subject in orthodontics that deserves serious revisiting in view of the relatively recent paradigm of inculcating evidence-based information in the orthodontic specialty and dental profession at large. Dental editors have a profound and often unap- preciated role in identifying such areas that might have far reaching and consequential effects upon individual patient care. Even more difficult is their task of finding capable and willing contributors to any appropriate journalistic or congress formats that might draw enthusiastic interest from our dental colleagues. The demand for no less than a 'debate' on this subject assumes that such a format is currently the most desirable and feasible vehicle of communication for exploration of the role of epigenetic and genetic contributions to malocclusion in modern civilisation. The initial challenge (after appropriate vetting of potential areas of dental interest), therefore, is to avoid unnecessary adversarial and often circus like presentations that discourage participation from interested communities and distracts us from our real purpose as clinicians, educators, researchers, editors, and dental congress programme designers. It is hoped that Dr Mew's letter will serve as a stimulus to the global community of dentistry and orthodontics to more seriously and robustly explore the importance of the aetiology of malocclusion in the formats of dental and orthodontic postgraduate curriculum, research, dental publications, and lecture presentations at our many dental meetings.

\section{E. M. Moskowitz New York DOI: 10.1038/sj.bdj.2010.454}

\section{A CAUTIOUS APPROACH}

Sir, I am currently working in an oral and maxillofacial surgery department of a district hospital where we are receiving progressively larger numbers of referrals of patients on bisphosphonates for extractions. 